\title{
İplik Düzgünsüzlük Analizi için Kapasitif Ölçüm Devresi Tasarımı: Matematiksel Yaklaşım ve Gerçekleme
}

\author{
Koray GÜRKAN*1[ \\ 1İstanbul Üniversitesi-Cerrahpaşa, Mühendislik Fakültesi, Elektrik-Elektronik Müh. Bölümü, 34320, İstanbul, \\ Türkiye
}

(Alınış / Received: 17.03.2019, Kabul / Accepted: 27.02.2020, Online Yayınlanma / Published Online: 20.04.2020)

\section{Anahtar Kelimeler}

Analog devre tasarımı, Kapasitif ölçüm,

Sensör,

İplik düzgünsüzlük
Özet: Tekstil sektörü, hızla gelişen ve Türkiye ihracatının büyük kısmını oluşturan bir sektör haline gelmiştir. Tekstil ürünlerinin dış piyasa ile rekabet edebilmesi için ürün kalitesinin artması gerekmektedir. Ürün kalitesi ise iplik kalitesine bağlı olarak değişebilmektedir. Bu çalışmada iplik kalitesini belirleyen parametrelerden biri olan iplik düzgünsüzlüguünün kapasitif olarak ölçümü için farksal paralel plaka yöntemine dayanan yeni bir ölçüm devresi önerisi yapılmış ve matematiksel olarak analiz edilmiştir. Paralel plakaların ve analog devrenin tasarım adımları, gerçeklenmesi, deney düzeneği anlatılmış ve ölçüm sonuçları irdelenmiştir. Tasarlanan devre ile düzgünsüzlük ölçümü oldukça hassas şekilde gerçekleștirilmiştir.

\section{Capacitive Measurement Circuit Design for Yarn Unevenness Analysis: Mathematical Approach and Realization}

\section{Keywords}

Analog circuit design, Capacitive measurement, Sensor, Yarn unevenness

\begin{abstract}
Textile sector has become a rapidly growing export sector constitutes a large part of Turkey. In order to compete with the foreign market, product quality needs to be increased. Product quality may vary depending on yarn quality. In this study, a new measurement circuit based on the differential parallel plate method was proposed and analyzed mathematically for the capacitive measurement of yarn unevenness, which is one of the parameters that determine the yarn quality. The design steps of the parallel plates and the analog circuit, their implementation, the experimental setup are explained and the measurement results are given. With the designed circuit, the yarn unevenness measurement was carried out very precisely.
\end{abstract}

\section{Giriş}

Düzgünsüzlük, iplik üretiminde iplik kalitesini etkileyen en önemli faktörlerden biridir. Kesikli liflerden yapılan ipliklerde lif uzunluk farkı, incelik farkl, bitkisel liflerde olgunluk farkı, hayvansal liflerde liflerin alındığı yer farkı gibi sebeplerden dolayı, ipliklerin birim uzunluklarında ağırlık, mukavemet, çap vb. varyasyonlar meydana gelmektedir [1]. İplikteki düzgünsüzlükleri iplik mukavemetinin düşmesine ince ya da kalın noktaların oluşmasına ve bu iplikle oluşan kumaşların boyanmasında lekeli ve bozuk görüntüye sebep olmaktadır. Üretilen ipliğin kalitesinin belirlenmesi ve standartların üzerinde olan düzgünsüzlüğün anında tespit edilebilmesi için en yaygın ölçüm yöntemi kapasitif ölçümdür. Kapasitif yöntemde iplik paralel plakalar arasından belirli bir

*ilgili yazar: kgurkan@istanbul.edu.tr hızda geçerken kesit alanı ya da kütlesiyle orantılı olarak kapasite değişimine yol açar. Bu değişimin doğrusal olması beklenir (Şekil 1).
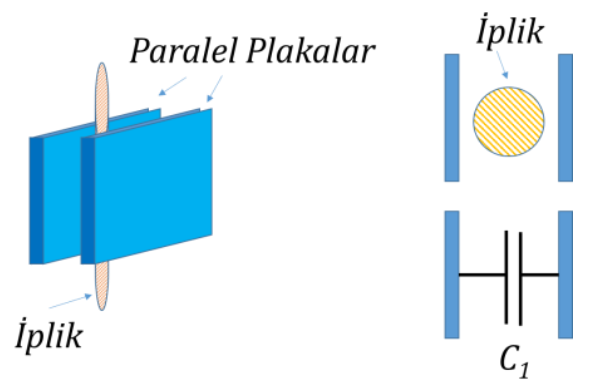

Şekil 1. İplik düzgünsüzlügünün kapasitif ölçümü

Aynı şartlar altında bu kapasitenin zamana göre değişimi ölçülürse ipliğin kütle değişimine ait iki önemli parametre olan düzgünsüzlük $\left(\begin{array}{ll}\% & U\end{array}\right)$ ve 
değişim katsayısı (\% $C V$ ) elde edilir. $U$ ve $C V$ aşağıdaki şekilde bulunur;

$$
\begin{gathered}
U=\frac{100}{\bar{x} T} \int_{0}^{T}\left|x_{i}-\bar{x}\right| d t \\
C V=\frac{100}{\bar{x}} \sqrt{\frac{1}{T} \int_{0}^{T}\left(x_{i}-\bar{x}\right)^{2} d t}
\end{gathered}
$$

Bu eşitliklerde $T$ ölçüm süresi, $x_{i}$ ipliğin anlık kütle değeri, $\bar{x}$ ölçüm süresi içerisindeki ortalama kütledir. Kütle değişimlerindeki hata da üç tür olarak sinıflandırılır. Kütlenin az olduğu alanlar ince yer, \% 100'den daha düşük olmak üzere kütlenin arttığı noktalar kalın yer ve \% 100 oranındaki kütle artışları olan noktalar Neps olarak adlandirılır [2].

Düzgünsüzlügün analizi ve hatalı noktaların yakalanabilmesi için kapasitif yöntemde kapasitenin ölçümü titiz bir çalışma gerektirmektedir. Ölçülen kapasitenin seviyesi oldukça düşük seviyelerde olduğundan paralel plakların ve analog devrenin tasarımında ekranlama, düşük gürültülü aktif elemanların kullanımı, nem ve sıcaklık gibi çevresel şartlara duyarsız ölçüm önemlidir. Tasarım iyi yapılmazsa hem kaçak kapasitelerden hem de değişen çevre şartlarından dolayı ölçüm devresi tutarsız sonuçlar verebilir ya da doyuma gidebilir.

Clive ve Slater [3], düzgünsüzlük ölçüm kapasitelerindeki elektrik alanın benzetimini yaparak paralel plaka etrafına yerleștirilecek koruma elektrodunun elektrik alan doğrusallığını arttırdığını ve koruma elektrodu olmadan alınan ölçümlerdeki hataların yok olduğunu göstermişlerdir.

Carvalho vd. [4], yaptıkları çalışmada $4 \mathrm{~mm}$ genişliğindeki plakalarla oluşturdukları kapasitenin ölçümünü 100 kHz'de hazır bir tümleşik devre (Microsensors, MS3110) kullanarak gerçekleştirmişlerdir. Devre kapasite değeriyle orantılı analog çıkış verdiğinden kapasite değişimini PCI-6024E veri toplama kartı ile $200 \mathrm{kHz}$ 'de alıp LabView programıyla analiz etmişlerdir. Tümleşik devre 10 pF'a kadar ölçüm yapabilmektedir.

Bir diğer çalışmada Pinto vd. [5], paralel plakaları bu kez $1 \mathrm{~mm}$ genişliğinde tasarlamış ve farksal ölçüm yöntemini uygulamışlardır. $\mathrm{Bu}$ yönteme göre sistemde iki farklı kapasite bulunmaktadır. Birincisi sadece havanın kapasitesini ölçerken diğeri ipliğin ve havanın kapasitesini ölçtüğünden diferansiyel ölçüm sağlamışlardır. Bu şekilde çevresel koşulların ölçüme etkisi azaltılmıştır.

Gang vd. [6] yaptıkları çalışmada kapasitif sensör için paralel plaka ile silindirik yapıdaki elektrot yapısının karşılaştırmalı olarak sonlu elemanlar yöntemi ile analiz etmişlerdir. Ayrıca hassas olarak kapasite değişimini gerilime çeviren ve otomatik olarak doyumu engelleyen bir devre önermişlerdir.

Bu çalışmalara ek olarak Zellweger Uster firmasının kapasitif elektrot tasarımına ilişkin patentleri bulunmaktadır [7-11]. Bu patentlerde de kapasite plakalarının nasıl olması gerektiği, üretim yöntemleri ve algılama elektroniği önerilmiștir. Kapasite farkının aşırı artması sonucu meydana gelebilecek doyumu engellemek amaciyla otomatik dengeleyici eklenmiştir.

Kapasitif yönteme ek olarak düzgünsüzlügün optik olarak ölçümüne yönelik çalışmalar da bulunmaktadır [12-18]. Bu yöntemler tamamen farklı bir prensipte çalıştığından bu makale kapsamında detaylarına girilmeyecektir.

Bu makalede iplik düzgünsüzlüğünün kapasitif olarak ölçümü için farksal paralel plaka yöntemine dayanan yeni bir ölçüm devresi önerisi yapılmış ve matematiksel olarak analiz edilmiştir. Paralel plakaların ve analog devrenin tasarım adımları, gerçeklenmesi, deney düzeneği ve ölçüm sonuçları irdelenmiştir.
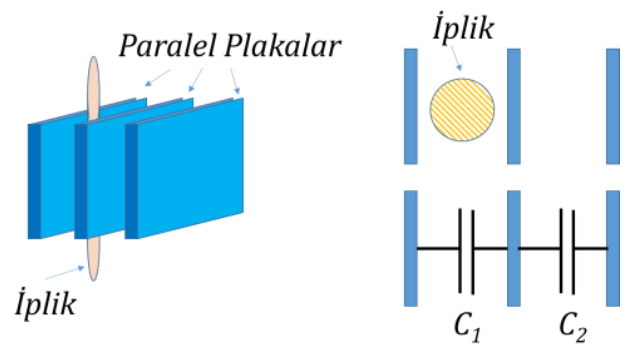

Şekil 2. İplik düzgünsüzlügünün farksal ölçümü

\section{Materyal ve Metot}

\section{1. Ölçüm devresinin tasarımı ve teorisi}

İplik düzgünsüzlüğünün kapasitif olarak ölçümü için önerilen devrenin blok şeması Şekil 3'te verilmiştir. $C_{1}$ ve $C_{2}$ Şekil 2'de belirtilen kapasitörleri ifade etmektedir. Bu kapasiteler farksal yapıda olan sensör yapısını oluşturmaktadır. Plaka mesafeleri farklı yapılarak iki ayrı farklı kalınlıkta ipin geçebileceği ölçüm ortamı yaratılmıştır. Ölçüm ortamındaki havanın dielektrik değişiminden kaynaklı etki iki kapasiteye aynı anda etkiyeceğinden bu ortak mod etki tasarlanan devre ile kompanze edilecektir. Burada $C_{1}$ içerisinden ip geçerken $C_{2}$ boştadır. Tam tersi durumda $C_{2}$ içerisinden ip geçerken $C_{1}$ de boşta bırakılabilir. Prensip olarak mutlaka bir plakanın boşta olması gerekmektedir. $V_{1}, V_{2}$ ve $V_{3}$ sinüzoidal kaynaklardır. $V_{a}$ kapasite bölücünün orta noktasındaki gerilim olup $K_{1}$ ile kuvvetlendirildikten sonra analog çarpıcıda $V_{3}$ ile çarpılarak $V_{b}$ gerilimini oluşturmaktadır. Yüksek frekanslı bileşenler alçak geçiren süzgeç ile süzüldükten sonra $K_{2}$ ile kuvvetlendirilerek $V_{o}$ çıkışını oluşturmaktadır. 


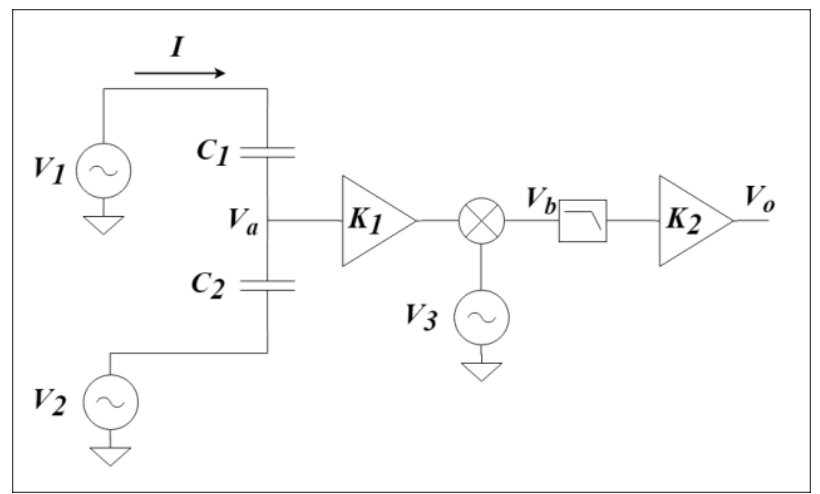

Şekil 3. Önerilen ölçüm yönteminin blok şeması

Şekil 3'teki devrede $I$ akımı aşağıdaki şekilde yazılabilir;

$$
I=Y_{e s}\left(V_{1}-V_{2}\right)
$$

Burada $Y_{e s}$; seri bağlı $C_{1}$ ve $C_{2}$ kapasitelerinin oluşturduğu eșdeğer admitanstır.

$$
Y_{e \varsigma}=s \frac{C_{1} C_{2}}{C_{1}+C_{2}}
$$

$V_{a}$ gerilimi;

$$
V_{a}=V_{1}-Y_{e s}\left(V_{1}-V_{2}\right) Z_{C_{1}}
$$

denklemi ile elde edilir. (3), (4) ve (5) yoluyla;

$$
V_{a}=V_{1} \frac{C_{1}}{C_{1}+C_{2}}+V_{2} \frac{C_{2}}{C_{1}+C_{2}}
$$

şeklinde düzlenebilir. $V_{1}$ ile $V_{2}$ kaynakları arasında $180^{\circ}, V_{1}$ ile $V_{3}$ kaynakları arasında $\theta$ kadar faz farkı olduğunu varsayarsak;

$$
\begin{aligned}
& V_{1}=A \cos (w t) \\
& V_{2}=A \cos (w t+\pi) \\
& V_{3}=A \cos (w t+\theta)
\end{aligned}
$$

$V_{b}$ gerilimi;

$$
\begin{gathered}
V_{b}=K_{1} V_{a} V_{3} \\
V_{b}=K_{1}\left[V_{1} V_{3} \frac{C_{1}}{C_{1}+C_{2}}+V_{2} V_{3} \frac{C_{2}}{C_{1}+C_{2}}\right]
\end{gathered}
$$

$V_{b}$

$$
\begin{aligned}
& =K_{1} \frac{A^{2}}{2}\left[\frac{C_{1}}{C_{1}+C_{2}}[\cos (\theta)+\cos (2 w t+\theta)]\right. \\
& \left.+\frac{C_{2}}{C_{1}+C_{2}}[\cos (\pi-\theta)+\cos (2 w t+\theta+\pi)]\right]
\end{aligned}
$$

Görüldüğü gibi çarpıcı çıkışındaki $V_{b}$ gerilimi kaynak frekanslarının iki katı frekansında titreșen sinüzoidal işaretten ve DC işaretten meydana gelmektedir. Yüksek frekanslı işaret alçak geçiren süzgece girip $K_{2}$ ile kuvvetlendirildiğinde $V_{o}$ çıkışı elde edilir;

$$
\begin{aligned}
V_{o}=K_{1} K_{2} \frac{A^{2}}{2}[ & \frac{C_{1}}{C_{1}+C_{2}} \cos (\theta) \\
& \left.+\frac{C_{2}}{C_{1}+C_{2}} \cos (\pi-\theta)\right]
\end{aligned}
$$

$\mathrm{Bu}$ durumda faz farkına göre çıkışın maksimum değerleri aşağıdaki şekilde bulunur;

$$
V_{o}= \begin{cases}K_{1} K_{2} \frac{A^{2}}{2}\left[\frac{C_{1}-C_{2}}{C_{1}+C_{2}}\right], & \theta=0 \\ K_{1} K_{2} \frac{A^{2}}{2}\left[\frac{C_{2}-C_{1}}{C_{1}+C_{2}}\right], & \theta=\pi\end{cases}
$$

Eşitlik 14'e göre $\theta=0$ için $C_{1}>C_{2}$ durumunda çıkış pozitif, aksi durumda negatif olacaktır. Şekil 2'deki paralel plakalar için $C_{1}$ ve $C_{2}$ kapasitelerini oluşturan levhaların yüzey alanları $S_{1}$ ve $S_{2}$, birbirine uzaklıkları $d_{1}$ ve $d_{2}$ ve ip kalınlığı $d_{\mathrm{i}}$ olsun. $\varepsilon_{0}$ vakumun dielektrik sabiti $\left(8.85 \times 10^{-12} \mathrm{~F} / \mathrm{m}\right), \varepsilon_{\mathrm{i}}$ ipin bağll dielektrik sabiti olmak üzere oluşan $C_{1}$ ve $C_{2}$ kapasiteleri aşağıdaki şekilde hesaplanabilir [6];

$$
C_{1}=\varepsilon_{0} \frac{s_{1}}{d_{1}-d_{i}+\frac{d_{i}}{\varepsilon_{1}}} \quad C_{2}=\varepsilon_{0} \frac{s_{2}}{d_{2}}
$$

Pratik olarak düzgünsüzlük miktarının $\% 100$ değerine çıkabileceği düşünülürse ipin levhalar arasından sürtünmeden geçebilmesi için $d_{1}$ mesafesinin, $d_{\mathrm{i}}$ değerinin iki katından daha büyük olması gerekir. Plakaların boyutlarında ipin hareketine paralel olan doğrultudaki yüzeyin uzunluğu düzgünsüzlük ölçümünün çcözünürlügünü belirler. İpin hareket doğrultusuna dik olan plaka yüzeyinin uzunluğu ise yine ip kalınlığına göre belirlenir ve ölçülmesi düşünülen ip kalınlığının en az iki katı olmalıdır. Plakaların yüzey alanı ve plaka mesafeleri için $S_{1}=S_{2}=S$ ve $d_{1}=d_{2}=d$ kabulü yapılıp $\theta=$ 0 için $V_{0}$ çıkışı hesaplanırsa;

$$
V_{o}=K_{1} K_{2} \frac{A^{2}}{2}\left[\frac{d_{i}\left(1-\frac{1}{\varepsilon_{i}}\right)}{2 d-d_{i}\left(1-\frac{1}{\varepsilon_{i}}\right)}\right]
$$

eşitliği elde edilir. Farklı plaka mesafesinin ve iplik kalınlığının $V_{o}$ çıkışına etkisini görselleştirebilmek adına keyfi olarak seçilen $K_{1}=K_{2}=1, \mathrm{~A}=10, \varepsilon_{i}=2$ durumu için dört farklı plaka mesafesinde iplik kalınlığına göre $V_{0}$ değișimi Şekil 4'te verilmiștir. Görüldüğü gibi plakalar yakınlaştıkça hassaslık artmasına rağmen iplik kalınlığı ile $V_{0}$ çıkışı arasındaki doğrusal ilişki bozulmaktadır. 


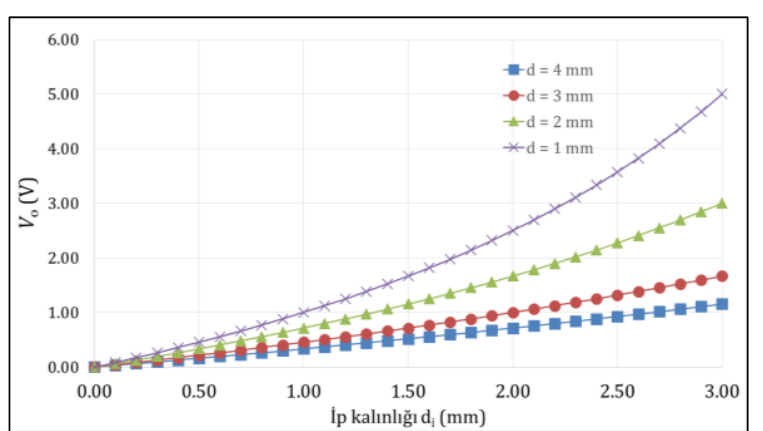

Şekil 4. Farklı plaka mesafeleri ve ip kalınlıkları için $V_{0}$ değişimi

\subsection{Gerçekleme}

Ölçüm yöntemi olarak önerilen Şekil 3'deki devrenin $V_{1}, V_{2}$ ve $V_{3}$ işaretleri tek bir sinüzoidal kaynaktan elde edilmiştir. Fonksiyon üretecinden alınan, sinüzoidal işaret sırasıyla hem evirmeyen hem de eviren devre topolojisi ile uygun ișlemsel yükselticilerle (Analog Devices, AD843) $20 \mathrm{~dB}$ kuvvetlendirilerek zit fazdaki $V_{1}$ ve $V_{2}$ gerilimleri elde edilmiştir. $\theta=0$ için $V_{3}=V_{1}$ olacağından $V_{3}$ kaynağı da sağlanmıştır. $V_{\text {a }}$ gerilimi ise $23 \mathrm{~dB}$ kuvvetlendirilerek analog çarpıcıya bağlanmıştır.

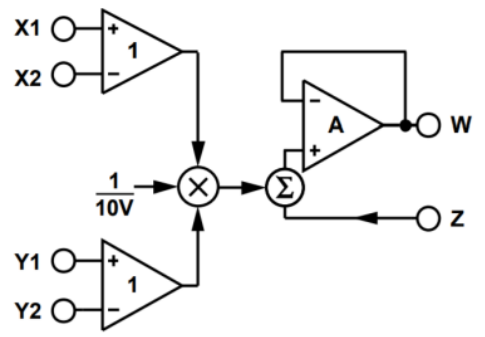

Şekil 5. Kullanılan analog çarpıcının blok şeması [19]

Kullanılan analog çarpıcının (Analog Devices, AD633) blok şeması Şekil 5'te görülmektedir. Çarpıcının transfer fonksiyonu $\mathrm{W}=(\mathrm{X} 1-\mathrm{X} 2) \cdot(\mathrm{Y} 1-\mathrm{Y} 2) / 10+\mathrm{Z}$ şeklindedir. $X 2$, $Y 2$ ve $Z$ girişleri toprak seviyesine çekildiğinde $\mathrm{W}$ çıkıșı X1 ve Y1 çarpımının 10'da biri olmaktadır. Böylelikle $V_{\mathrm{b}}$ çıkışı da elde edilmiştir. $V_{\mathrm{b}}$ çıkışındaki işaret kesim frekansı $50 \mathrm{~Hz}$ olan alçak geçiren süzgeç ile süzüldükten sonra kazancı ayarlanabilir bir evirmeyen yükseltici ile kuvvetlendirilerek (ST, TL081) $V_{0}$ çlkışı elde edilmiştir. Devredeki tüm işlemsel yükselticiler ve analog çarpıcı +/- 12V DC ile beslenmiştir.

\subsection{Paralel plakaların tasarımı ve üretimi}

Kapasitörü oluşturan paralel plakalar iki ayrı grup şeklinde tasarlanmıştır. Ortadaki plakalar uç plakalardan farklı olarak koruma elektrotu ve algılama elektrotundan oluşmaktadır. Algılama elektrotu ile koruma elektrotu ölçüm devresinde elektriksel olarak aynı potansiyele getirilerek kaçak kapasitenin oluşması engellenmiştir. Algılama elektrotunun boyutu kapasitenin alanını belirlemektedir ve denemeler için $4.2 \mathrm{~mm}$ x $4.2 \mathrm{~mm}$ olacak şekilde tasarlanmıştır (Şekil 6). Uç plakaların sınırı ise koruma elektrotu ile aynı boyuttadır. Paralel plakalar arasındaki mesafe $3 \mathrm{~mm}$ olacak şekilde tasarım yapılmıştır. Bu parametrelere göre $C_{1}$ (iplik yokken) ve $C_{2}$ kapasiteleri hesaplandığında teorik olarak 0.052 pF'lık kapasite değeri elde edilmektedir.

Tüm plakalar PCB prototipleme makinesi (MITS Electronics, ElevenLab) ile kazıma yoluyla $1.6 \mathrm{~mm}$ kalınlığında $30 \mu \mathrm{m}$ bakır yüzeyi olan FR4 malzemeden üretilmiştir.

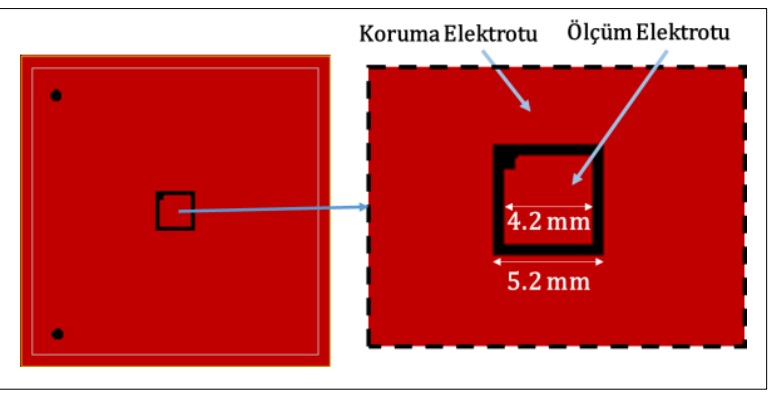

Şekil 6. Orta bölümdeki paralel plakaların yapısı

\subsection{Testler}

İplik düzgünsüzlük ölçümü için kurulan devrenin statik testi için fonksiyon üretecinden (Rigol, DG1062) alınan frekansı $200 \mathrm{kHz}$ ve tepe değeri 500 $\mathrm{mV}$ olan sinüzoidal işaret devreye uygulanmıştır. İp sabitken frekansın ve genliğin çıkış işaretine etkisi, çarpıcı çıkışı ve devre çıkışı incelenmiş bu amaçla $V_{0}$ ve $V_{\mathrm{b}}$ çıkışı sayısal osiloskop (Rigol, MS01074) ekranında görüntülenmiştir. Dinamik test için ipliğin ileri ve geri yönde ölçüm plakalarını ortalayacak şekilde hareket edebilmesini sağlayan düzenek ve kapasitif plakaları sabitleyen kaide Pro-Ser Tekstil Test Cihazları Ltd. Şti. desteğiyle üretilmiştir (Şekil 7). Mekanik hareketi sağlayan adım motorunun devri ayarlanarak iplik hareketi istenilen hıza getirilmiş ve devrenin dinamik tepkisi incelenmiştir.

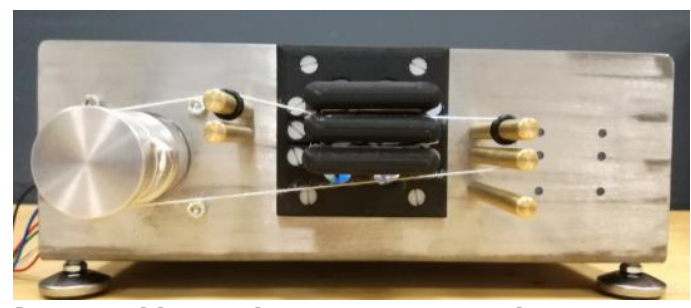

Şekil 7. Gerçeklenen ölçüm sisteminin önden görünümü

\section{Bulgular}

Devrenin statik testinde ortalama kalınlığı $0.4 \mathrm{~mm}$ olan iplik kullanıldığında işaret frekansı $200 \mathrm{kHz}$ için işaret genliği arttıkça çıkıştaki DC kayıklığın arttığı gözlenmiştir. Ölçülen değerlere göre eğri uydurulduğunda değişimin karesel olduğu görülmektedir (Şekil 8). Frekans artışı da aynı etkiyi yapmıştır (Şekil 9). Uygulunan işaret frekansı 200 $\mathrm{kHz}$ için çıkış işareti ip yokken $6.44 \mathrm{~V}$, ip plakalar arasına girdiğinde $8.54 \mathrm{~V}$ ölçülmüştür. 


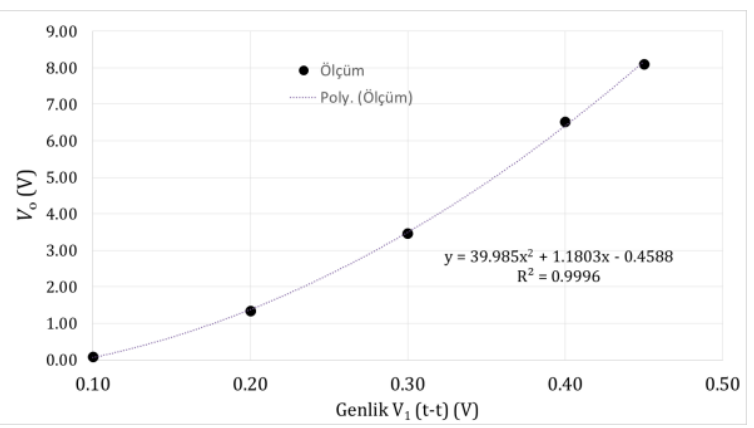

Şekil 8. Çıkıș işaretinin uygulanan işaret genliğine göre değișimi

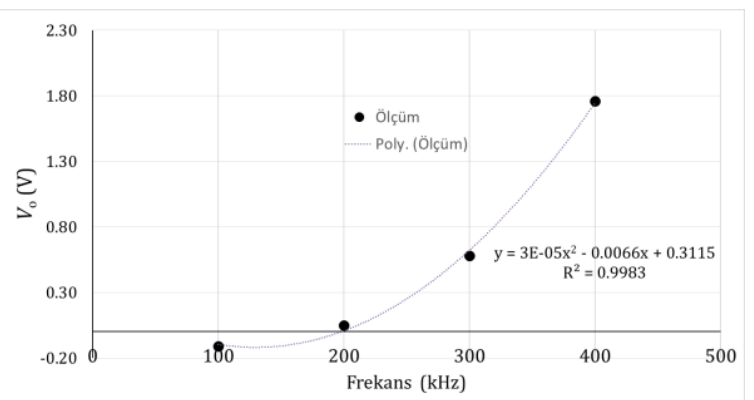

Şekil 9. Çıkıș işaretinin uygulanan işaret frekansına göre değişimi

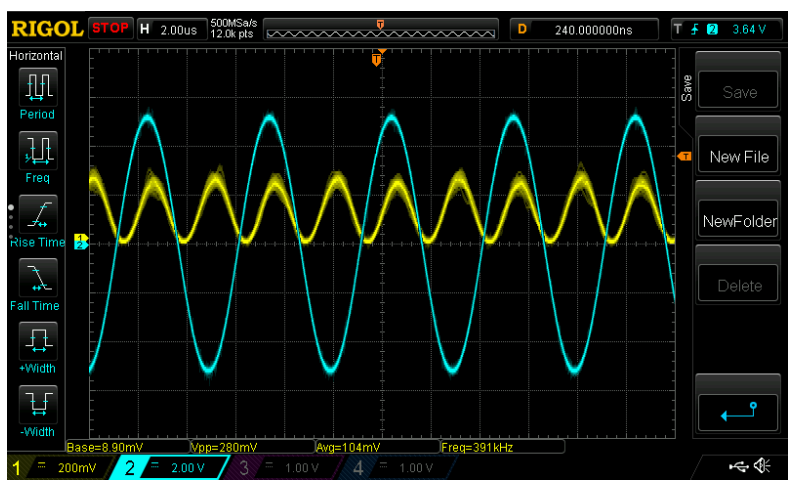

Şekil 10. $V_{1}$ işaret kaynağı (mavi) ve çarpıcı çıkışında ölçülen işaret (sarı)

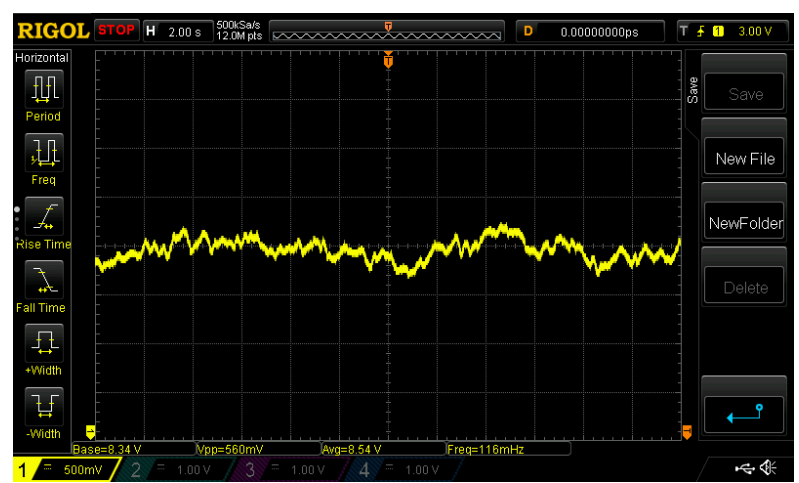

Şekil 11. Sistemin el ile hareketiyle çıkış işaretinin osiloskoptan alınan değișimi

Şekil 3'teki prensip devredeki $V_{1}$ işaret kaynağı ile çarpıcının çıkışı olan $V_{\mathrm{b}}$ noktasındaki işaretin gerçeklenen devreden ölçülen osiloskop görüntüsü Şekil 10'da verilmiştir. Çarpıcı çıkışında belirli bir kayıklıkta $V_{1}$ frekansının iki katı frekansında (400 $\mathrm{kHz}$ ) sinüzoidal işaret görülmektedir.

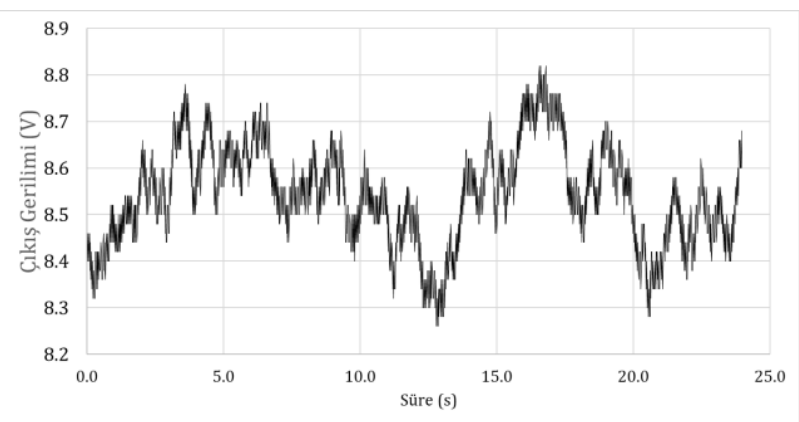

Şekil 12. Sistemin el ile hareketiyle çıkış işaretinin değişimi

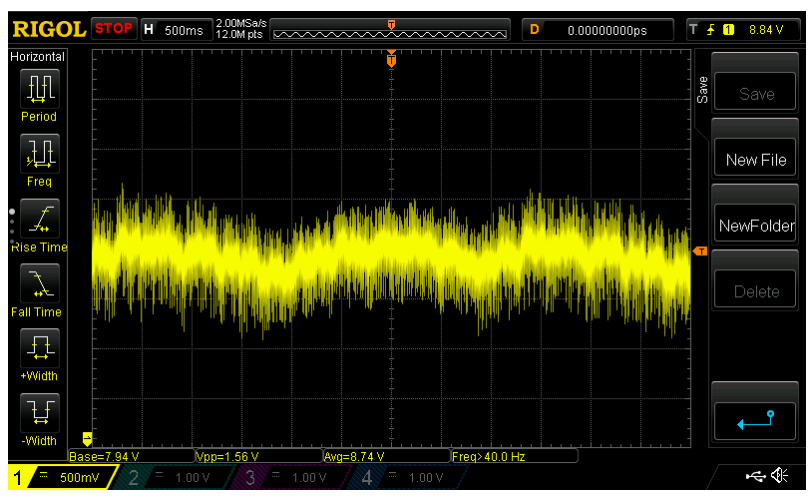

Şekil 13. Otomatik hareketi ile çıkış işaretinin değişimi

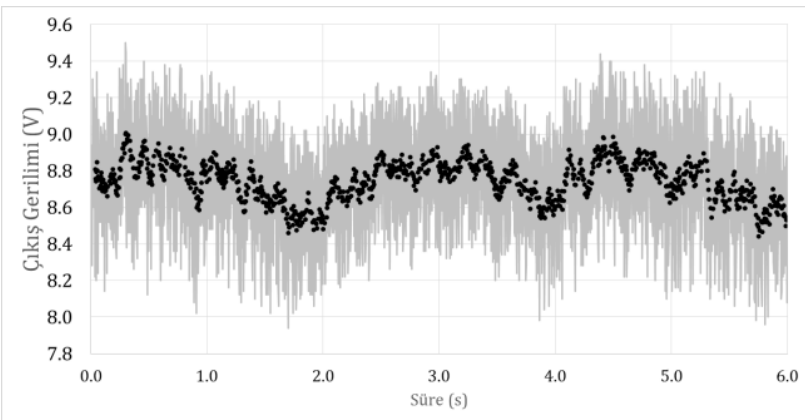

Şekil 14. Gürültüsü giderilmiş çıkıș işareti

Sistemin elle tek yönde döndürülmesi ile ip kalınlığındaki değişimden dolayı çıkışın etkilenmesi Şekil 11'de görülmektedir.

Osiloskop verilerinin bilgisayara alınarak detaylı çizdirilmesi sonucu elde edilen grafik Şekil 12'de verilmiştir. Durağan halde $8.54 \mathrm{~V}$ okunan değer ipin geçişiyle +/-280 mV'lik değişim göstermiştir. Standart sapma $110 \mathrm{mV}$ olarak hesaplanmıştır.

Adım motoru çalıştırılarak belirli bir süre ileri ve daha sonra geri yönde $0.145 \mathrm{~m} / \mathrm{s}$ hızda iplik hareketi verildiğinde alınan çıkış gerilimi Şekil 13'te verilmiştir. Motor sargılarından kaynaklanan elektromanyetik akım darbelerinin sistem çıkışını etkilediği görülmektedir.

Gürültünün giderilmesi amacıyla, osiloskoptan alınan veriler Excel ortamına aktarılmıștır. Ham durum için standart sapma 374 mV'dir. Kayan ortalama süzgeci ile süzülen verinin istatistik analiz için kullanılabilir hale gelebildiği görülmüştür (Şekil 14). 
Şekil 14'te ipin hareket yönü 3. saniyede değişmektedir. Eğriye dikkatle bakıldığında 3 . saniyeye göre simetriktir. Bu da ölçülen gerilimdeki değişimin önce ileri daha sonra geri yönde ilerleyen ip kütlesindeki değişimden kaynaklandığını doğrulamaktadır. Gerilim değerinin standart sapma değeri ipin kütle değişiminden kaynaklanan standart sapma değeri ile orantılı olacaktır. $\mathrm{Bu}$ nedenle düzgünsüzlük ve değişim katsayısı belirli bir ölçek farkıyla hesaplanabilir.

\section{Tartışma ve Sonuç}

İplik düzgünsüzlügünü kapasitif olarak ölçmek üzere önerilen devre teorik ve pratik olarak doğrulanmıştır. Devre çıkışının, uygulanan sinüzoidal işaret genliği ile karesel olarak değişmesi analiz sonucu ulaşılan çıkış denklemi ile uyuşmaktadır. Devre çıkışının iplik yokken sıfır değerine gelmemiş olması paralel plakaların oluşturduğu $C_{1}$ ve $C_{2}$ kapasite değerlerinin eşit olmadığını göstermektedir. Devrede ölçülmesi hedeflenen ve femto Farad seviyelerindeki kapasiteler kaçak kapasitelerin etkisiyle dengesizleştiğinden devrenin yüksek kazancı ile beraber çıkışı yüksek bir kayıklık seviyesine getirmektedir. Devrenin çıkışında iplik varken ve yokken ölçülen DC değerler devrenin oldukça hassas çalıştığını göstermektedir. İpliğin hareket ettiği durumda da çıkış işaretindeki değişimin net görülmesi bu sonucu doğrulamaktadır. Önerilen devre ile iplik düzgünsüzlüğü net olarak gözlenmiştir. Düzgünsüzlük analizi için daha uzun ip geçişi sağlayan düzenek ile daha uzun süreli kayıt alınması planlanmaktadır. Yapılacak yeni çalışmalarla hareket mekanizmasındaki gürültünün etkisi azaltılacak, sıcaklık ve nemin çıkıșa olan etkisi farklı iplikler için incelenecektir.

\section{Teşekkür}

Bu çalışma Pro-Ser Tekstil Test Cihazları Ltd. Şti. tarafından desteklenmiştir.

\section{Kaynakça}

[1] Goswami, B.C., Martindale, J.G., Scardino, F.L. 1977. Textile Yarns: Technology, Structure and Applications. John Wiley and Sons. New York, 482s.

[2] Gries, T. and Veit, D. Wulfhorst, B. 2015. Textile Technology: An Introduction. Carl Hanser Verlag GmbH \& Co. KG, 457s.

[3] Nancy K. Clive, K. Slater. 1974. Simulation of the Electric Field in Evenness-Testing Capacitors, The Journal of The Textile Institute, 65(8), 397401.

[4] Carvalho, V., Pinto, J. G., Monteiro, J., Vasconcelos, R. M., Soares, F. O. 2003. On-line measurement of yarn evenness. IEEE
International Symposium on Industrial Electronics, 9-11 Haziran, Brezilya, 1059-1064.

[5] Pinto, J. G., Carvalho, V., Monteiro, J. L., Vasconcelos, R. M., Soares, F. O. 2007. Yarn-mass Measurement with 1-mm-length Samples. IEEE Transactions on Industrial Electronics, 54(2), 1177-1183.

[6] Gang, Y., Entao, Y., Shencun, H., Ning, J. 2016. The research on High Sensitivity and Antisaturation of Capacitance Sensors for Measuring Yarn Evenness. 10th International Conference on Sensing Technology (ICST), 11-13 Kasım, Çin, 1-6.

[7] Hoffmann, D. 1973. Measuring Capacitor. United States Patent, US3754172A, 1-4.

[8] Geiter, P., Rolf, J. 1999. Methode and Device for Measuring the Solid Proportion of a Material Under Test. European Patent Office, EP0924513A1, 1-10.

[9] Ott, P., Schmid, P. 2008. Device and Method for Examining a Solid, Elongate Product to be Tested. United States Patent, US20080111563A1, 1-11.

[10] Gehrig, R., Phillipp, O., Rolf, J. 2014. Capacitive Measuring Circuit for Yarn Inspection. United States Patent, 8698510, 1-10.

[11] Peters, G., Vries, L. D., Storz, R. 2016. Electrode Assembly for Capacitively Testing an Elongated Textile Material. World Intellectual Property Organization, W02016149842A1, 1-21.

[12] Carvalho, V., Cardoso, P., Belsley, M., Vasconcelos, R. M., Soares, F. O. 2006. Development of a Yarn Evenness Measurement and Hairiness Analysis System. 32nd Annual Conference on IEEE Industrial Electronics, 6-10 Kasım, Fransa, 3621-3626.

[13] Carvalho, V. H., Belsley, M. S., Vasconcelos, R. M., Soares, F. O. 2009. Automatic Yarn Characterization System: Design of a Prototype. IEEE Sensors Journal, 9(8), 987-993.

[14] Carvalho, V., Belsley, M., Vasconcelos, R., Soares, F. 2011. A comparison of Mass Parameters Determination Using Capacitive and Optical Sensors. Sensors and Actuators A: Physical, 167(2), 327-331.

[15] Sparavigna, A., Broglia, E., Lugli, S. 2004. Beyond Capacitive Systems with Optical Measurements for Yarn Evenness Evaluation. Mechatronics, 14(10), 1183-1196. 
[16] Ozkaya, Y. A., Acar, M., Jackson, M. 2005. Digital Image Processing and Illumination Techniques for Yarn Characterization. Journal of Electronic Imaging, 14(2), 023001, 1-13.

[17] Sengupta, A., Roy, S., \& Sengupta, S. 2015. Development of a Low Cost Yarn Parameterisation Unit by Image Processing.
Measurement, 59, 96-109.

[18] Li, G., Akankwasa, N. T., Zhao, Q., \& Wang, J. 2019. A Novel System for Yarn Cross-Section Analysis Based on Dual Orthogonal CCD Sensors. Journal of Natural Fibers, 16(1), 114-125.

[19] Analog Devices. 2019. http://www.analog.com (Erişim Tarihi: 28.02.2019). 